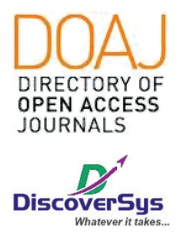

Published by DiscoverSys

\section{Pengaruh ekstrak kulit buah naga merah (Hylocereus polyrhizus) terhadap kadar malondialdehyde (MDA) Paru pada tikus yang diberi paparan asap rokok}

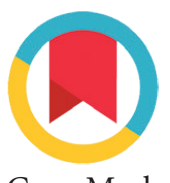

CrossMark

\author{
Raditya Pradipta, ${ }^{1 *}$ IGN Sri Wiryawan, ${ }^{2}$ I Wayan Sugiritama ${ }^{2}$
}

\section{ABSTRACT}

Background: Peel of a red dragon fruit (Hylocereus Polyrhizus) is rarely utilized which is usually just thrown way, even though it contains such high antioxidants such as phenols, flavonoids and also anthocyanins. Methods: This study aims to determine the effect of red dragon fruit skin extract (Hylocereus Polyrhizus) on MDA levels of lung in rats exposed to cigarette smoke. This research is an experimental study with Post-Test Only Control Group Design. The sample consisted of 30 rats aged 2-3 months which were divided into 5 groups each amounting to 6 rats, namely 1 negative control group was not given exposure to cigarette smoke, 1 group of positive cock was exposed to cigarette smoke, 3 treatment groups were given exposure cigarette smoke and administration of red dragon fruit skin extract with doses of $20 \mathrm{mg}, 40 \mathrm{mh}$ and $80 \mathrm{mg}$ for 14 days. The parameters measured were MDA levels of the lung.

Results: The mean MDA level of lung control group 1 was $0.146 \pm 0.02$ $\mathrm{nmol} / \mathrm{ml}$, the mean of control group 2 was $0.166 \pm 0.01 \mathrm{nmol} / \mathrm{ml}$, the mean of treatment group 1 was $0.168 \pm 0.03 \mathrm{nmol} / \mathrm{ml}$, treatment group 2 was $0.153 \pm 0.02 \mathrm{nmol} / \mathrm{ml}$, and treatment group 3 was 0.776 $\pm 0.09 \mathrm{nmol} / \mathrm{ml}$. The significance analysis with the One Way Anova test shows that the value of $F=1.34$ and the value of $p=0.282$, where the value of $p>0.05$

Conclusion: There was no significant difference between the control group and the treatment group or between treatment group 1 , treatment 2 and treatment 3.

Keywords: red dragon fruit (Hylocereus Polyrhizus), malondialdehyde, lung

Cite This Article: Pradipta, R., Wiryawan, I.G.N.S., Sugiritama, I.W. 2019. Pengaruh ekstrak kulit buah naga merah (Hylocereus polyrhizus) terhadap kadar malondialdehyde (MDA) Paru pada tikus yang diberi paparan asap rokok. Intisari Sains Medis 10(3): 806-810. D0I: 10.15562/ism. v10i3.484

\title{
ABSTRAK
}

Latar Belakang: Kulit buah naga merah (Hylocereus Polyrhizus) merupakan limbah yang sangat jarang dimanfaatkan, biasanya kulit buah naga merah hanya dibuang begitu saja, padalah mengandung antioksidan yang begitu tinggi seperti fenol, flavonoid dan juga antiosianin.

Metode: Penelitian ini bertujuan untuk mengetahui pengaruh ekstrak kulit buah naga merah (Hylocereus Polyrhizus) terhadap kadar MDA paru pada tikus yang dipaparkan asap rokok. Penelitian ini merupakan penelitian eksperimental dengan Post-Test Only Control Group Design. Sampel terdiri dari 30 ekor tikus yang berumur 2-3 bulan yang dibagi menjadi 5 kelompok masing-masing berjumlah 6 ekor tikus, yaitu 1 kelompok kontrol negative tidak diberikan paparan asap rokok, 1 kelompok kontrol positif diberikan paparan asap rokok, 3 kelompok perlakuan diberikan paparan asap rokok dan pemberian ekstrak kulit buah naga merah dengan dosis $20 \mathrm{mg}, 40 \mathrm{mg}$ dan $80 \mathrm{mg}$ selama 14 hari. Parameter yang diukur adalah kadar MDA paru.

Hasil: Rerata kadar MDA paru kelompok kontrol 1 adalah 0,146 $\pm 0,02$ $\mathrm{nmol} / \mathrm{ml}$, rerata kelompok kontrol 2 adalah 0,166 $\pm 0,01 \mathrm{nmol} / \mathrm{ml}$, rerata kelompok perlakuan 1 adalah 0,168 $\pm 0,03 \mathrm{nmol} / \mathrm{ml}$, kelompok perlakuan 2 adalah $0,153 \pm 0,02 \mathrm{nmol} / \mathrm{ml}$, dan kelompok perlakuan 3 adalah 0,776 $\pm 0,09 \mathrm{nmol} / \mathrm{ml}$. Analisis kemaknaan dengan uji One Way Anova menunjukan bahwa nilai $F=1,34$ dan nilai $p=0,282$, dimana nilai $p>0,05$

Simpulan: Tidak ada perbedaan yang bermakna antara kelompok kontrol dengan kelompok perlakuan maupun antara kelompok perlakuan 1, perlakuan 2 dan perlakuan 3.
TProgram Studi Pendidikan Dokter Fakultas Kedokteran Universitas Udayana

${ }^{2}$ Departemen Histologi Fakultas Kedokteran Universitas Udayana

*Korespondensi: Raditya Pradipta, Program Studi Pendidikan Dokter, Fakultas Kedokteran Universitas Udayana

radityadipta@yahoo.com

Diterima: 06-04-2019

Disetujui: 21-11-2019

Diterbitkan: 01-12-2019
Kata kunci: buah naga merah (Hylocereus Polyrhizus), malondialdehyde, paru

Cite Pasal Ini: Pradipta, R., Wiryawan, I.G.N.S., Sugiritama, I.W. 2019. Pengaruh ekstrak kulit buah naga merah (Hylocereus polyrhizus) terhadap kadar malondialdehyde (MDA) Paru pada tikus yang diberi paparan asap rokok. Intisari Sains Medis 10(3): 806-810. D0I: 10.15562/ism.v10i3.484

\section{PENDAHULUAN}

Rokok telah menjadi masalah kesehatan yang sangat serius terutama di negara berkembang termasuk Indonesia. Jumlah perokok setiap tahun di Indonesia meningkat secara signifikan. Menurut survei nasional, jumlah perokok di Indonesia pada tahun 2010 berkisar 34,7\% dan pada tahun 2013 naik menjadi 36,3\%. ${ }^{1}$ 
World Health Organization (WHO) memperkirakan tahun 2025 jumlah perokok di Indonesia akan meningkat sekitar $45 \%$ dari total populasi. Peningkatan jumlah perokok di Indonesia tidak hanya memberikan dampak yang buruk bagi kesehatan, namun terhadap berbagai aspek ekonomi, sosial, dan juga politik. Kerugian biaya kesehatan yang dikeluarkan diakibatkan rokok mencapai enam kali lebih besar daripada cukai rokok yang didapat pemerintah. Penurunan daya kerja penduduk karena rokok mengakibatkan produktivitas kerja secara nasional menurun. Selain itu, peningkatan jumlah perokok aktif di Indonesia akan diimbangi dengan peningkatan jumlah perokok pasif sehingga Pemerintah RI membuat kebijakan yang mengatur kawasan bebas rokok untuk mengurangi dampak asap rokok. ${ }^{1}$

Salah satu efek tidak langsung dari kebiasaan merokok adalah menyebabkan mortalitas dengan meningkatkan berbagai penyakit degeneratif pada beberapa sistem organ. ${ }^{2}$ Kerusakan pada berbagai sistem organ tersebut disebabkan oleh berbagai macam zat toksik dalam bentuk gas maupun zat kimia yang volatil, iritan dan radikal bebas yang ada dalam asap rokok. Penelitian secara epidemiologi terhadap efek merokok sudah banyak dilakukan dan terbukti bahwa merokok telah meningkatkan risiko terkena COPD (Chronic Obstructive Pulmonary Disease), kanker paru-paru, dan penyakit-penyakit kardiovaskuler. ${ }^{3}$ Semua penyakit tersebut berkaitan dengan meningkatnya stres oksidatif dan berkurangnya antioksidan endogen akibat dari peningkatan radikal bebas yang masuk ke tubuh. ${ }^{4}$

Radikal bebas yang terkandung dalam asap rokok dapat menimbulkan keadaan stres oksidatif pada tubuh dimana terjadi ketidakseimbangan antara antioksidan dan radikal bebas. Banyaknya paparan radikal bebas yang masuk ke dalam tubuh, sehingga enzim yang terdapat di dalam tubuh seperti Superoxide Dismutase (SOD), katalase dan Gluthathion Peroxidase (GSH-PX) dan antioksidan yang diproduksi tubuh seperti glutation, koenzim Q10 dan melatonin tidak mampu meredam semua efek radikal bebas. Ketidakseimbangan antara radikal bebas dan antioksidan di dalam tubuh menghasilkan stres oksidatif. Stres oksidatif dapat menyebabkan terjadinya peroksidasi lipid. Peroksidasi lipid dapat ditentukan dengan mengukur produk akhir berupa malondialdehid (MDA). Kondisi stres oksidatif dapat diinduksi oleh berbagai faktor seperti kurangnya antioksidan dan kelebihan produksi radikal bebas. Keadaan ini dapat mempengaruhi proses-proses fisiologis maupun biokimia tubuh, yang mengakibatkan terjadinya gangguan metabolisme fungsi sel dan dapat berakhir pada kematian sel. ${ }^{5}$
Antioksidan adalah senyawa yang dapat mengurangi, menahan dan mencegah proses oksidasi yang disebabkan oleh radikal bebas. ${ }^{6}$ Menurut Ingold yang dikutip oleh Gordon (1990), antioksidan dapat diklasifikasikan ke dalam dua kelompok, yaitu antioksidan primer yang dapat bereaksi dengan lipid radikal dan membentuk produk stabil, serta antioksidan sekunder yang dapat mengurangi kecepatan inisiasi. ${ }^{7}$ Selain antioksidan primer dan sekunder, juga terdapat antioksidan lain yaitu antioksidan enzimatik intrasel (seperti superoxide dismutase/SOD, katalase, danglutation peroksidase), yang terdapat dalam jaringan tubuh. Enzim antioksidan berperanan penting baik secara langsung dalam proteksi sel terhadap stres oksidatif, spesies oksigen reaktif (ROS), dan secara tidak langsung menjaga keseimbangan beberapa spesies oksigen toksik. ${ }^{8}$ Pembentukan antioksidan alami yang dihasilkan sendiri oleh tubuh tidak cukup untuk melawan radikal bebas yang ada di dalam tubuh sehingga dibutuhkan asupan antioksidan dari luar tubuh.

Buah naga merah (Hylocereus polyrhizus) sebagai buah yang dikenal banyak oleh masyarakat karena rasa daging buahnya yang enak dan harganya yang juga terbilang murah ternyata memiliki manfaat lain yang tidak banyak diketahui. Tingkat konsumsi buah naga yang semakin meningkat, berdampak terhadap sisa kulit yang hanya dibuang begitu saja. Kulitnya yang mempunyai berat sekitar 22\% dari berat buah belum dimanfaatkan secara optimal dan hanya dibuang sebagai sampah sehingga dapat menyebabkan pencemaran lingkungan. Bagian dari buah naga 30-35\% adalah kulit yang biasanya hanya dibuang sebagai sampah dan jarang dimanfaatkan. Padahal kulit dari buah naga ini ternyata memiliki potensi antioksidan yang dapat digunakan untuk melawan efek dari radikal bebas yang menyebabkan berbagai penyakit.

\section{METODE}

Penelitian ini merupakan penelitian eksperimental dengan Post-Test Only Control Group Design. Penelitian dilakukan di Laboraturium Fakultas Kedokteran Universitas Udayana untuk mengetahui kadar MDA dari organ Paru tikus putih (Rattus norvegicus) jantan galur Sprague dawley yang telah diberikan ekstrak kulit buah naga merah (Hylocereus Polyhriuz), per-oral. Waktu penelitian adalah selama bulan september-oktober 2018.

Sampel penelitian adalah 30 ekor tikus putih (Rattus norvegicus) jantan galur Wistar berjenis kelamin jantan, berat badan sekitar 150-200gram dan berusia sekitar kurang lebih 3-4 bulan (dewasa) yang diperoleh dari Laboratorium Histologi. 
Sampel dibagi menjadi 5 kelompok masing masing berjumlah 6 ekor yang dipilih secara acak yaitu K1 (Kelompok kotrol negatif), K2 (kelompok kontrol positif), P1, P2, P3 (Kelompok Perlakuan). Kelompok K2, P1, P2, P3 diberikan pemaparan rokok selama 14 hari. Kelompok P1, P2, P3 masing - masing diberi ekstrak kulit buah naga merah dengan dosis $20 \mathrm{mg}, 40 \mathrm{mg}, 80 \mathrm{mg}$. Kelompok K1 tidak diberikan pemaparan asap rokok maupun ekstrak kulit buah naga merah. Selama penelitian tikus tetap diberi makan dan minum standar secara ad libitum, dan selama penelitian berlangsung tidak ada sampel yang mengalami kematian (drop out).

Setelah pemajanan selama 14 hari selesai, tikus dilakukan euthanasia menggunakan ketamine dengan dosis $125 \mathrm{mg} / \mathrm{KgBb}$ secara intramuscular dalam anaerobic jar. Pengambilan organ paru dilakukan dengan cara pembedahan pada abdomen tikus. Organ paru - paru diambil, lalu ditimbang beratnnya $20 \mathrm{mg}$. Kemudian dicincang menjadi halus dan dimasukan ke dalam tabung sentrifus yang telah diberi label untuk diambil supernatanya. Ditambahkan $1 \mathrm{ml}$ PBS-KCl (PBS dingin yang mengandung $\mathrm{KCl}$ ) ke tiap-tiap tabung sentrifus, lalu diaduk dengan batang pengaduk hingga rata. Kemudian disentrifus $15.000 \mathrm{rpm}$ selama lima belas menit dengan suhu $4^{\circ} \mathrm{C}$. Kemudian diambil suprenatanya sebanyak $0,5 \mathrm{ml}$ dari tiap-tiap sampel, lalu ditambahkan $2 \mathrm{ml}$ larutan campuran TCA-TBA (dihomogenkan). Larutan homogen disimpan dalam oven dengan suhu $80^{\circ} \mathrm{C}$ selama 1 jam. Setelah satu jam lalu diangkat dan didinginkan pada suhu ruangan. Kemudian dilakukan dilakukan sentrifus $3000 \mathrm{rpm}$ selama 15 menit. Pembacaan kadar

Table 1 Statistik deskriptif

\begin{tabular}{lcc}
\hline Kelompok & Total Sampel $(\mathbf{n})$ & Mean \pm Std. Deviasi $(\mathbf{n m o l} / \mathbf{m l})$ \\
\hline K1 & 6 & $0,146 \pm 0,02$ \\
K2 & 6 & $0,166 \pm 0,01$ \\
P1 & 6 & $0,168 \pm 0,03$ \\
P2 & 6 & $0,153 \pm 0,02$ \\
P3 & 6 & $0,776 \pm 0,09$ \\
\hline
\end{tabular}

Table 2 Uji Normalita Data

\begin{tabular}{llcccc}
\hline & & \multicolumn{3}{c}{ Shapiro-Wilk } & \multirow{2}{*}{ Keterangan } \\
\cline { 3 - 5 } Kelompok & & Statistic & df & Sig. & \\
\hline \multirow{2}{*}{ MDA PARU } & K1 &, 882 & 6 & 0,277 & \\
& K2 &, 749 & 6 & 0,190 & Normal \\
& P1 &, 824 & 6 & 0,095 & \\
& P2 &, 980 & 6 & 0,950 & \\
& P3 &, 865 & 6 & 0,208 & \\
\hline
\end{tabular}

Catatan $={ }^{*}$ distribusi normal jika $\mathrm{p}>0,05$
MDA dengan menggunakan sprektrofometer pada panjang gelombang $\lambda 532 \mathrm{~nm}$.

Data yang diperoleh dari hasil pengukuran kadar MDA pada paru dianalisis menggunakan program SPSS versi 20.0. Hasil penelitian dianalisis apakah memiliki distribusi normal atau tidak secara statistik dengan uji normalitas Shapiro-Wilk karena jumlah sampel $\leq 50$. Kemudian, dilakukan uji Levene untuk mengetahui apakah dua atau lebih kelompok data memiliki varians yang sama atau tidak, dilanjutkan dengan metode uji parametrik oneway ANOVA. Hipotesis dianggap bermakna bila $\mathrm{p}<0,05$.

\section{HASIL}

Pada tabel 1 ditampilkan kadar MDA paru dengan rata-rata pada kelompok kontrol dan kelompok perlakuan. Dari hasil tersebut menunjukan bahwa rerata kadar MDA paru kelompok kontrol 1 adalah $0,146 \pm 0,02 \mathrm{nmol} / \mathrm{ml}$, rerata kelompok kontrol 2 adalah $0,166 \pm 0,01 \mathrm{nmol} / \mathrm{ml}$, rerata kelompok perlakuan 1 adalah $0,168 \pm 0,03 \mathrm{nmol} / \mathrm{ml}$, kelompok perlakuan 2 adalah $0,153 \pm 0,02 \mathrm{nmol} / \mathrm{ml}$, dan kelompok perlakuan 3 adalah $0,776 \pm 0,09 \mathrm{nmol} / \mathrm{ml}$.

Data kemudian diuji menggunakan uji normalitas. Dalam penelitian eksperimen ini terdapat 30 sampel yang digunakan, oleh karena itu uji normalitas yang akan digunakan adalah shapiro-wilk. Data disebut berdistribusi normal jika hasil $\mathrm{p}>0,05$. Hasil uji normalitas menggunakan Shapiro-Wilk pada sampel ini adalah terdistribusi normal (Tabel 2). Kemudian data dari 5 kelompok dianalisis menggunakan Uji Levene. Dimana hasil uji homogenitas pada 5 kelompok adalah homogen oleh karena nilai $\mathrm{p}>0,05$ (Tabel 3).

Analisis kemaknaan dengan uji One Way Anova menunjukan bahwa nilai $\mathrm{F}=1,34$ dan nilai $\mathrm{p}=0,282$, dimana nilai $\mathrm{p}>0,05$ (Tabel 4).

\section{DISKUSI}

Kulit buah naga merah (Hylocereus Polyrhizus) memiliki kandungan antioksidan yang lebih tinggi dibandingkan jenis yang putih. Kulit buah naga mengandung vitamin $\mathrm{C}$, vitamin $\mathrm{E}$, vitamin $\mathrm{A}$, alkaloid, terpenoid, flavonoid, tiamin, niasin, piridoksin, kobalamin, fenolik, karoten, dan fitoalbumin. ${ }^{9}$ Menurut penelitian Wu, et al (2006) keunggulan dari kulit buah naga yaitu kaya polifenol dan merupakan sumber antioksidan. Selain itu aktivitas antioksidan pada kulit buah naga lebih besar dibandingkan aktivitas antioksidan pada daging buahnya, sehingga berpotensi untuk dikembangkan menjadi sumber antioksidan alami. ${ }^{10}$ aktivitas antioksidan kulit buah naga juga didukung dengan penelitian oleh Mitasari (2012) 
Table 3 Uji Homogenitas Data

\begin{tabular}{lccccc}
\hline Variabel $(\mathbf{n m o l} / \mathbf{m l})$ & Levene Statistik & df1 & df2 & Sig. & Keterangan \\
\hline MDA & .529 & 4 & 25 & 0.715 & Homogen \\
\hline
\end{tabular}

Catatan $={ }^{\star}$ homogen jika $\mathrm{p}>0,05$

Tabel 4 Uji Perbandingan Antara Kelompok

\begin{tabular}{lcccc}
\hline Kelompok & Total Sampel $(\mathbf{n})$ & Mean \pm Std. Deviasi $(\mathbf{n m o l} / \mathbf{m l})$ & $\mathbf{F}$ & Sig. $(\mathbf{p})$ \\
\hline K1 & 6 & $0,146 \pm 0,02$ & & \\
K2 & 6 & $0,166 \pm 0,01$ & \\
P1 & 6 & $0,168 \pm 0,03$ & 1,341, & \\
P2 & 6 & $0,153 \pm 0,02$ & \\
P3 & 6 & $0,776 \pm 0,09$ & \\
\hline
\end{tabular}

yang menyatakan bahwa ekstrak kloroform kulit buah naga merah memiliki aktivitas antioksidan dengan nilai IC50 sebesar 43,836 $\mu \mathrm{g} / \mathrm{mL}$. $^{11}$

Radikal Bebas yang terdapat di dalam asap rokok merupakan molekul biologik yang mempunyai satu atau lebih elektron yang tidak berpasangan pada orbit terluarnya, sehingga menyebabkan elektron ini tidak stabil dan sangat reaktif dapat merusak jaringan. Paparan asap rokok merupakan salah satu faktor utama meningkatnya radikal bebas dalam tubuh, adapun penyebab lainnya seperti asap kedaraan, sinar UV, asap dari pabrik dan sebagainya. Proses tersebut akan menghasilkan ROS berlebih yang merupakan oksidan utama dalam tubuh. ${ }^{12}$

Peningkatan radikal bebas dalam tubuh menyebabkan ketidakseimbangan antara oksidan dengan antioksidan yang ada didalam tubuh sehingga menyebabkan stres oksitdatif. Mekanisme sel atau jaringan yang paling awal diketahui dan banyak diteliti adalah peroksidasi lipid. Kulit buah naga mengandung pigmen antosianin yang dapat bertindak sebagai antioksidan. Adanya kemampuan antosianin untuk memangsa radikal bebas yang langsung berasal dari asap rokok maupun radikal bebas yang timbul akibat respon inflamasi, maka antosianin dapat menekan terjadinya peroksidasi lipid dan juga menekan produksi MDA sehingga kadar MDA menurun. Antosianin dengan cepat dapat mengikat ion logam untuk membentuk komplek antosianin-logam yang stabil. Hal tersebut menjelaskan bahwa antosianin mengikat logam transisi Fe sehingga dapat dicegah terjadinya pembentukan reaksi hidroksil yang sangat toksik dan reaktif. Pada akhirnya antosianin dapat menekan terjadinya peroksidasi lipid dan juga menekan produksi MDA sehingga kadar MDA menurun. ${ }^{13}$

Berdasarkan hasil pengujian menggunakan Uji Anova pada penelitian ini didapatkan hasil yang tidak signifikan (nilai $\mathrm{p}$ sebesar $=0,28$ ) yang berarti tidak adanya perbedaan kadar MDA yang signifikan antar kelompok. Namun menurut hasil penelitian ini, terjadi tren penurunan rerata kadar MDA yang terjadi pada kelompok P1, P2, dan P3 dibandingkan dengan kelompok kontrol.

Perlakuan pada sampel penelitian ini yaitu dengan memberikan paparan asap rokok selama 30 menit per hari pada tiap kelompok selama 14 hari. Berbeda dengan perlakuan dari studi yang dilakukan oleh Nasution (2016) yang meneliti tentang Efek Preventif Pemberian Ekstrak Kulit Buah Naga Berdaging Super Merah (Hylocereus Costaricensis) terhadap Malondialdehid Tikus Wistar yang Dipapar Asap selama 28 hari menunjukkan peningkatan kadar MDA yang bermakna $(\mathrm{p}<0,05))$ pada kelompok yang dipapar asap rokok dengan rerata $10,6222 \pm 1,595 \mathrm{nmol} / \mathrm{ml}$ dibandingkan dengan kelompok yang tidak mengalami paparan asap rokok dengan rerata $4,041 \pm 0,901 \mathrm{nmol} / \mathrm{ml} .{ }^{14}$ Hal tersebut menunjukkan bahwa asap rokok merupakan sumber radikal bebas yang dapat meningkatkan kadar MDA. Dalam hal ini lama waktu pemaparan dapat berpengaruh terhadap perubahan kadar malondialdehide yang disebabkan karena keadaan stress oksidatif akibat paparan asap rokok.

Selain dari durasi pemaparan asap rokok, dosis pemberian ekstrak kulit buah naga merah dalam penelitian ini yaitu $20 \mathrm{mg}, 40 \mathrm{mg}$, dan $80 \mathrm{mg}$. Dengan penggunaan dosis ini masih belum didapatkan hasil uji anova yang signifikansi $\mathrm{p}=0,28(\mathrm{p}>0,05)$. Hal ini bertentangan dengan hasil studi yang dilakukan oleh Septiana (2016) yang meneliti tentang efek pemberian seduhan kulit buah naga merah terhadap malonadildehyde tikus sprague dawley dislipidemia yang dibagi menjadi 5 kelompok yaitu K-, $\mathrm{K}+, \mathrm{P} 1, \mathrm{P} 2$ dan P3. Kelompok perlakuan 1, 2 dan 3 diberi diet tinggi lemak selama 7 hari, lalu diberi diet standar tikus serta seduhan kulit buah naga merah dengan dosis $200 \mathrm{mg} / \mathrm{ml}, 400 \mathrm{mg} / \mathrm{ml}$ dan $800 \mathrm{mg} / \mathrm{ml}$ selama 14 hari berikutnya. Hasil analisis One Way Annova diperoleh nilai signifikansi 
0,000 $(\mathrm{p}<0,05)$, dapat disimpulkan bahwa terdapat perbedaan rerata kadar MDA plasma antar kelima kelompok atau terdapat efek seduhan kulit buah naga terhadap kadar MDA plasma dengan rerata kadar MDA plasma pada kelompok kontrol negatif sebesar 1,2 $\pm 0,09 \mathrm{nmol} / \mathrm{ml}$, kelompok kontrol positif sebesar $5,7 \pm 0,12 \mathrm{nmol} / \mathrm{ml}$, kelompok perlakuan I sebesar 3,3 $\pm 0,17 \mathrm{nmol} / \mathrm{ml}$, kelompok perlakuan II sebesar 2,1 $\pm 0,22 \mathrm{nmol} / \mathrm{ml}$ dan kelompok perlakuan III sebesar $1,7 \pm 0,18 \mathrm{nmol} / \mathrm{ml} .{ }^{15} \mathrm{Hal}$ ini membuktikan bahwa pemberian dosis tinggi pada kelompok hewan coba berpengaruh terhadap perbedaan rerata MDA antar kelompok yang diuji.

\section{KETERBATASAN}

Studi ini dilakukan dalam waktu yang singkat yaitu 14 hari, efek terhadap paparan kronik sulit diperkirakan. Sulit dievaluasi efek dari ekstrak buah naga merah yang diberikan pada masing-masing tikus karena Studi ini tidak membandingkan hasil pre-test dan post-test.

\section{SIMPULAN}

Hasil uji statistik menunjukkan tidak ada perbedaan bermakna antara kelompok kontrol dengan kelompok perlakuan maupun antara kelompok perlakuan 1, perlakuan 2 dan perlakuan 3. Tidak ada pengaruh ekstrak kulit buah naga merah (Hylocereus Polyrhizus) terhadap kadar MDA paru pada tikus yang dipaparkan asap rokok.

\section{KONFLIK KEPENTINGAN}

Penulis menyatakan tidak terdapat suatu konflik kepentingan terhadap publikasi dari artikel ini.

\section{PENDANAAN}

Penelitian ini tidak mendapatkan suatu pendanaan yang diberikan oleh pemerintah ataupun lembaga swasta lainnya.

\section{KONTRIBUSI PENULIS}

Konsep penelitian: Raditya Pradipta, IGN Sri Wiryawan, I Wayan Sugiritama. Pengumpulan data, input data dan pengolahan data: Raditya Pradipta. Penyusunan naskah Penelitian: Raditya Pradipta.

\section{ETHICAL CLEARANCE NUMBER}

\author{
2298/UN14.2.2.VII.14/LP/2018.
}

\section{DAFTAR PUSTAKA}

1. Suryadinata RV., Wirjatmadi B. \& Adriani M. Efektivitas Penurunan Malondialdehyde dengan Kombinasi. 2017. $5(2)$.

2. Burns, David. Nicotine Addiction. In: Harrison T.R. Harrison's Priciples of Essential fatty acids of pitaya seed oil. Journal of Food Chemistry. 2005.114:561-564.

3. Boots AW, Haenen GRMM, and Bast A. Oxidant metabolism in chronic obstructive pulmonary disease. Eur Respir J. 2003. 22:14S27S.

4. Barnoya J \& Glantz SA. Cardiovascular effects of secondhand smoke. Circulation. 111:2684-2698

5. MacNee W \& Rahman I. 1999. Oxidants and antioxidants as therapeutic targets in chronic obstructive pulmonary disease. Am J Respir Crit Care Med. 2005. 160: S58-S65.

6. Schuler P. Natural Antioxidant Exploited Commercially. In: Hudson B.J.F. 1990.

7. Gordon MH. The Mechanism of Antioxidant Action in vitro. In: Hudson, B.J.F. 1990.

8. Touati D. Regulation and Protective Role of the Microbial Superoxide Dismutases. In: Scandalios (ed), Molecular Biology of Free Radical Scavenging Systems. Cold Spring Harbor Laboratory Press. 1992. p231 261.

9. Jaafar, Ali R., Nazri M., dan Khairuddin W. Proximate Analysis of Dragon Fruit (Hylecereus polyhizus), American Journal of Applied Sciences. Jakarta: EGC. 2009.

10. Wu LC., Hsu HW., Chen YC., Chiu CC., Lin YI., dan Ho JA. Antioxidant and antiproliperative activities of red pitaya. Journal of Food Chemistry. 2006. 95:319-327.

11. Mitasari A. Uji Aktivitas Ekstrak Kloroform Kulit Buah Naga Merah (Hylocereus polyrhizus Britton \& Rose) Menggunakan Metode DPPH (1,1- Defenil-2-Pikril Hidrazil), Skripsi, Program Studi Farmasi, Universitas Tanjungpura. 2012. 37-38.

12. Muliartha IKG, Sriwahyuni E, dan Yuliawati. Oral Comsumption of Combined Vitamin C and E Repair Liver Damage Due to Subchronic Exposure to Cigarette. Jurnal Kedokteran Brawijaya. 2009. 24(10): 23-27.

13. Miguel MG. Antioxidant Activity of Medicinal andAromatic Plants. A Review. Flavour and Fragrance Journal. 2010. 25(5): 291-312.

14. Nasution A., Wirjatmadi B. and Adrian, M. Efek Preventif Pemberian Ekstrak Kulit Buah Naga Berdaging Super Merah (Hylocereus Costaricensis) terhadap Malondialdehid Tikus Wistar yang Dipapar Asap Rokok. Jurnal Kedokteran Brawijaya. 2016. 29(1).

15. Septiana W. and Ardiaria M. Efek Pemberian Seduhan Kulit Buah Naga Merah (Hylocereus polyrhizus) Terhadap Kadar Malondialdehyde (Mda) Tikus Sprague Dawley Dislipidemia. Journal of Nutrition College. 2016. 5(4).

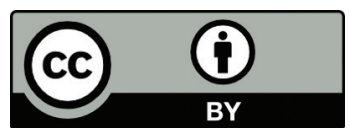

This work is licensed under a Creative Commons Attribution 